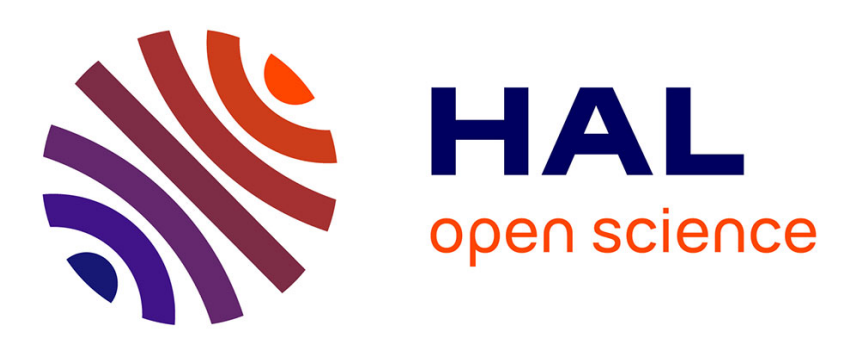

\title{
Mass deacidification and reinforcement of papers and books VI - Study of aminopropylmethyldiethoxysilane treated papers
}

\author{
Anne-Laurence Dupont, Bertrand Lavédrine, Herve Cheradame
}

\section{To cite this version:}

Anne-Laurence Dupont, Bertrand Lavédrine, Herve Cheradame. Mass deacidification and reinforcement of papers and books VI - Study of aminopropylmethyldiethoxysilane treated papers. Polymer Degradation and Stability, 2010, 95, pp.2300 - 2308. 10.1016/j.polymdegradstab.2010.09.002 . hal01491194

\author{
HAL Id: hal-01491194 \\ https://hal.science/hal-01491194
}

Submitted on 22 Mar 2017

HAL is a multi-disciplinary open access archive for the deposit and dissemination of scientific research documents, whether they are published or not. The documents may come from teaching and research institutions in France or abroad, or from public or private research centers.
L'archive ouverte pluridisciplinaire HAL, est destinée au dépôt et à la diffusion de documents scientifiques de niveau recherche, publiés ou non, émanant des établissements d'enseignement et de recherche français ou étrangers, des laboratoires publics ou privés. 


\title{
Mass deacidification and reinforcement of papers and books VI - Study of aminopropylmethyldiethoxysilane treated papers
}

\author{
A.-L. Dupont ${ }^{\mathrm{a}, *}$, B. Lavédrine ${ }^{\mathrm{a}}$, H. Cheradame ${ }^{\mathrm{b}}$ \\ ${ }^{a}$ Centre de Recherche sur la Conservation des Collections, Muséum national d'histoire naturelle, USR CNRS 3224,36 rue Geoffroy-Saint-Hilaire, 75005 Paris, France \\ ${ }^{\mathrm{b}}$ Laboratoire Matériaux Polymères aux Interfaces, UMR CNRS 7581, Université d'Evry, Bld F. Mitterrand, 91025 Evry, France
}

\section{A R T I C L E I N F O}

\section{Article history:}

Received 2 June 2010

Received in revised form

2 September 2010

Accepted 13 September 2010

Available online 19 September 2010

\section{Keywords:}

Paper

Deacidification

Reinforcement

Oxidation

Aminoalkylalkoxysilanes

Artificial ageing

\begin{abstract}
A B S T R A C T
In libraries and archives some of the items which, upon ageing, have acidified considerably since their production are so brittle that they cannot be handled without risking loss of material. In contrast to current deacidification processes, aminoalkylakoxysilanes (AAAS) improve the mechanical properties of paper. A simple AAAS, aminopropylmethyldiethoxysilane (AMDES) was used as a model to better understand previous observations made on these systems (hydrolysis, condensation and possible reactions with the organic substrate). The evaluation of the mechanical properties of papers that were treated with AMDES showed that there was no formation of a polymer network on the fibres' surface. However, treated papers not only exhibited a high alkaline reserve, but also a significant increase in both their tensile breaking length and their folding endurance. Treatment of hygrothermally aged papers with AMDES provided improved folding endurance as well as a good resistance to ageing. Various oxidation treatments of the model papers using sodium hypochlorite led to the conclusion that the nature of the oxidised groups formed on cellulose did not seem to play a significant role in the strengthening mechanism but rather that this effect of AMDES mainly arose from hydrogen bonding between the two molecules.
\end{abstract}

(c) 2010 Elsevier Ltd. All rights reserved.

\section{Introduction}

Mass deacidification of books and paper documents is a chemical process involving the neutralisation of the acids present in paper and the deposition of an alkaline compound such as calcium carbonate (often referred as 'alkaline reserve') to prevent, or at least delay, further acidification. It is a key issue for libraries and archives trying to ensure the long-term preservation of paper-based items that have become acidic, and it is often the sole conservation treatment solution for a wide range of 19th and 20th century books. Indeed, the main cause of decay of paper is its acid content in combination with time of exposure. The sources of acid in paper can be endogenous, i.e. related to the composition of the paper, or exogenous, i.e. related to the environment. In the latter case, for instance the contact with atmospheric pollutants such as nitrogen oxides found in various concentration in libraries and archives located in urban areas [1-3], and the contact with volatile organic acids produced during the natural ageing of the paper itself or by enclosure materials do promote degradation [4-8]. In previous publications, a liquid phase deacidification process based on aminoalkylalkoxysilanes (AAAS)

\footnotetext{
* Corresponding author.

E-mail addresses: aldupont@mnhn.fr (A.-L. Dupont), lavedrin@mnhn.fr (B. Lavédrine), herve.cheradame@univ-evry.fr (H. Cheradame).
}

was described $[9,10]$. It was shown that the contact with 3-aminopropyltrimethoxysilane (ATMS) and similar silanes containing amine and alkoxysilyl functions could efficiently deacidify, and at the same time deposit an alkaline reserve in the paper. It is worth mentioning that the chemistry of the process, which involves polycondensation between silanol groups, is consistent with the goals of green chemistry [11], which encourages products and processes that minimize the use and generation of hazardous substances, and involves non harmful chemical compounds which are undamaging for cellulosic substrates. The solvent used in the first tests was ethanol. Later, the use of a non protic solvent, hexamethyldisiloxane (HMDS), which involves weak van der Waals interactions, was reported as an improvement in the process, due to better dimensional stability of the paper [12,13].

The behaviour of AAAS treated papers upon ageing has been investigated [14]. Indeed, the long-term stability of these amine compounds in paper can be of concern, due to the potential deamination process that may occur when a hydrogen atom is present in the $\beta$ position of a nitrogen atom. To address this issue, 4-amino-3,3dimethylbutyltrimethoxysilane (ADMBTMS), which bears no such hydrogen, and which is commercially available, was introduced. The paper treated with ADMBTMS showed improved tensile mechanical resistance, even after artificial ageing with high heat and humidity, as well as a significantly increased folding endurance $[14,15]$. 
The reason for this improved performance brought about by ageing is not yet well understood. Several hypotheses can be proposed which involve chemical bonds between AAAS and cellulose. Firstly, a reaction can occur upon heating a paper that contains ADMBTMS, involving the silanol groups and the hydroxyl functions of cellulose [16,17]. Secondly, the primary amine group of the AAAS could react with cellulose via the chain ends or via the carbonyl and carboxyl groups produced along the chain during the ageing by the oxidation reactions taking place. The result would be a network firmly bound on the fibres' surface. One could also reasonably assume that such effects would occur at room temperature upon long-term storage (natural ageing). The latter is an important issue to be investigated as the AAAS based treatment is, to our knowledge, the only process applicable for mass treatment that, besides efficient deacidification, alkaline reserve deposition [14] and antifungal properties [18], would also offer the paper both immediate and long-term improvement of its mechanical resistance.

These hypotheses for the mechanism of the reinforcement observed thus need to be confirmed with further investigation. However, the number of relevant parameters to be studied in order to understand the physical chemistry of the process is hardly understandable at once. In the frame of a fundamental study and in an attempt to simplify the system and discriminate between the hypotheses that could explain the reinforcement effect induced by AAAS in paper, it was decided to test one AAAS only, 3-aminopropylmethyldiethoxysilane (AMDES), on a model paper made of pure cellulose. The main reason for choosing AMDES was that after hydrolysis and silanol condensation, this AAAS can yield linear macromolecules only via polycondensation of bifunctional molecules (Fig. 1). It is well known that such reaction leads to oligomers of limited length. Consequently, assuming that silanol condensation is the only bond forming reaction, no three dimensional network can be formed, and there would be no polymer network interpenetrated in the cellulose fibres. Conversely, the condensation of trifunctional silanes, such as ADMBTMS, at the fibres' surface could create such a cross-linked network.

As in a mass deacidification process the use of a non protic solvent with a low solubility parameter is strongly advocated as it limits fibre swelling and dissolution of the polar substances present in the paper [12], it was decided to use HMDS in all the experiments reported here. Some aspects of the role of the solvent have been addressed elsewhere [13].

\section{Experimental}

\subsection{Materials}

The paper henceforth called P2 is made of cotton linters (>95\%) with traces of softwood pulp, and contains no fillers or sizing (basis weight $76 \mathrm{~g} \mathrm{~m}^{-2}$, cold extract $\mathrm{pH}=6.2$ ). The paper henceforth called P3 is made of $75 \%$ ground wood pulp and $25 \%$ softwood cellulose (basis weight $80 \mathrm{~g} \mathrm{~m}^{-2}$, cold extract $\mathrm{pH}=5.1$ ). P3 contains $20 \%$ kaolin filler and is sized with alum-rosin and traces of casein. Both papers were specially made at a paper mill in The Netherlands in 1990 for the STEP project [19].

A naturally aged book printed in 1928, henceforth called B1928, made of $50 \%$ ground wood pulp and $50 \%$ chemical pulp was also used (cold extract $\mathrm{pH}=4.7$ ).

\subsection{AAAS solutions and paper impregnation process}

3-aminopropylmethyldiethoxysilane (AMDES) was used as received, with no further purification. Hexamethyldisiloxane (HMDS) was distilled prior to use. Both chemicals were purchased from ABCR (Gelest, France). Treatment solutions were prepared directly by dissolving AMDES in HMDS. The solutions were stored at room temperature in brown glass bottles. Unless otherwise stated, sheets of paper (A4 size) were immersed for $10 \mathrm{~min}$ in the treatment solution at room temperature in open air. They were then slightly pressed between two blotters in order to eliminate the excess solution, and dried under vacuum for $3 \mathrm{~h}$ at room temperature. Once dry, the AMDES uptake in the papers pre-conditioned at $23{ }^{\circ} \mathrm{C}$ and $50 \%$ relative humidity $(\mathrm{rH})$ was determined (\% wt/wt).

Control papers were not subjected to any treatment as it was shown that after immersion in HMDS with subsequent drying and preconditioning following the protocol explained above, the paper showed unmodified mechanical properties.

\subsection{Physico-chemical determinations}

The moisture content (MC) (\% wt/wt) and the cold extract $\mathrm{pH}$ of the papers were determined according to TAPPI standards T 412 om02 and T509 om-88, respectively, with a mass of paper of $50 \mathrm{mg}$.

The alkaline reserve (AR) ( $\mathrm{meq}\left(\mathrm{OH}^{-}\right) / 100 \mathrm{~g}$ ) was determined by back-titration according to the standard method ASTM D498896R01. Initial acidity $\left(\mathrm{meq}\left(\mathrm{H}^{+}\right) / 100 \mathrm{~g}\right)$ was determined according to CCPA standard G.25P.

The AMDES uptake (\% wt/wt) was measured by weighing the samples pre-conditioned at $23{ }^{\circ} \mathrm{C}$ and $50 \%$ rH before and after treatment. This method was preferred over the method based on the alkaline reserve measurement as it has been previously shown that the latter yielded underestimated uptake values, which was attributed to the fact that not all the amine functions were available to titration.

All the measurements described above were repeated at least three times per sample type. Only the average values are given.

The copper number ( $\mathrm{Cu}$ no.) was determined according to TAPPI standard T $430 \mathrm{~cm}-99$, with a mass of paper of $300 \mathrm{mg}$. The method is based on the fact that oxidised cellulose is capable of reducing certain metallic ions to lower valence states, and that reactions of this type can serve to estimate the quantity of reducing groups. The copper number may be regarded as an index for compounds which possess reducing properties (e.g. oxidised cellulose, lignin, and

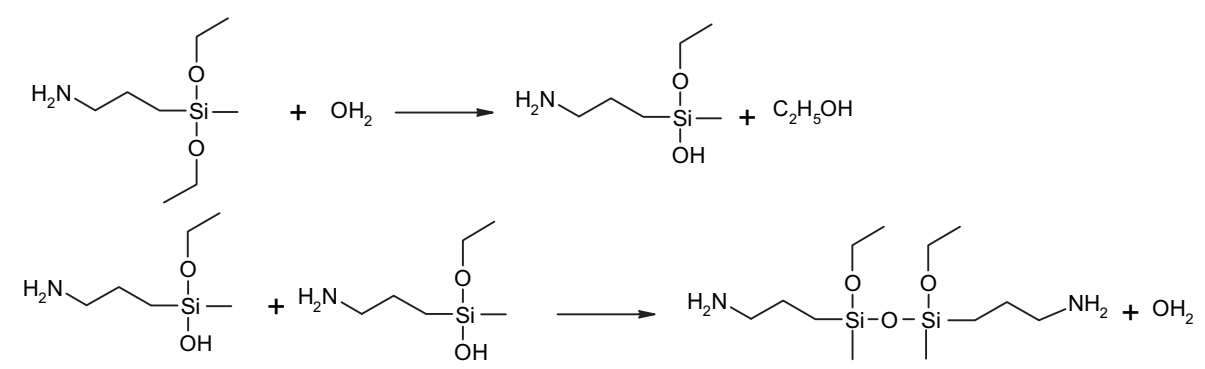

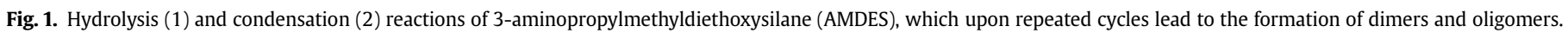


sugars). Three to nine repeat measurements were done for each sample type and only the average value of $\mathrm{Cu}$ no. is given $\left(\mathrm{g} \mathrm{Cu}_{2} \mathrm{O}\right)$.

Mechanical properties were determined in the machine direction of the papers, unless otherwise stated, on the samples conditioned at $23{ }^{\circ} \mathrm{C}$ and $50 \% \mathrm{rH}$. Tensile breaking length (BL) (km) and tensile elongation at break (TE) (\%) were measured with an Adamel Lhomargy instrument (DY-20B), according to the standard method NF: Q03-004 July 1986. Samples were tested at a speed of $2 \mathrm{~mm} \mathrm{~min}^{-1}$, with the 100 DaN load cell. Zero-span tensile strength (zsTS) was measured with a Pulmac instrument (TS 100), also according to NF Q 03-004. Dry zsTS was measured on samples as conditioned. Wet zsTS was measured after saturating the paper sample with water for $1 \mathrm{~min}$ prior to mounting in the pulling jaws. Wetting the paper allows to eliminate inter-fibre bonding, and intrinsic fibre bonding alone to be measured. The data is then normalised to the sample width with $\left(\mathrm{P}-\mathrm{P}_{0}\right) / 15\left(\mathrm{psi} \mathrm{mm}^{-1}\right)$, $\mathrm{P}_{0}$ being an instrumental constant. For all the mechanical tests performed, ten repeat measurements were carried out using ten strips taken from the same sample. Only the average value is given. The values of BL and zsTS of P2 paper (often quoted as control values) can differ from one set of experiments to another within the experimental precision and for this reason, control values were determined for each series of experiments. Folding endurance (FE) (number of folds) was determined with a Tinius Olsen double fold instrument, according to ISO 5626:1993.

Concerning the level of precision of the measurements, it was experimentally shown that the tensile breaking length could be determined within $\pm 6 \%$ in each set of experiments, while the tensile elongation at break and the zero-span tensile strength had a precision of $\pm 10 \%$. As expected, folding endurance was determined with a lower precision of $\pm 15 \%$. As for the alkaline reserve and initial acidity measurements, the precision depended mostly on the evenness of the treatment, and was estimated to be within $\pm 10 \%$. Error bars on the graphs correspond to this standard percentage error estimated based on the precision of the measurement except when indicated in the figures captions.

\subsection{Oxidation pre-treatment}

Sheets of paper were immersed at room temperature in sodium hypochlorite $(\mathrm{NaOCl})$ solutions at $1.3 \%$ active chlorine, at neutral $\mathrm{pH}$, before treating the paper with AMDES. The papers were then thoroughly rinsed by immersing twice in deionised water. After gentle pressing, the papers were dried under vacuum at room temperature.

\subsection{Artificial ageing}

Two different artificial ageing procedures were used. One, based on ASTM D6819-02e2, involved placing the paper in a tightly closed glass vessel which is heated to $100{ }^{\circ} \mathrm{C}$ for various durations $(2,5$ and 10 days). This procedure is intended to simulate a real situation inside a book or a stack of paper, where the cellulosic material remains in contact with the degradation products as they form. The paper was previously conditioned at $23{ }^{\circ} \mathrm{C}$ and $50 \% \mathrm{rH}$, which allows buffering the humidity inside the closed tube around $50 \% \mathrm{rH}$.

The second accelerated ageing procedure involved five days exposure to $50 \mathrm{ppm} \mathrm{NO}_{2}$ at $23{ }^{\circ} \mathrm{C}$ and $50 \% \mathrm{rH}$, according to the ASTM D6833-02E01, in a Servathin ventilated oven.

\subsection{Molar mass determinations}

Size-exclusion chromatography with multiangle light scattering detection (SEC-MALS) was used for the determination of the average molar mass of cellulose. An isocratic HPLC pump 515 (Waters) and autosampler ACC-3000T (Dionex) were part of the chromatographic set-up, together with a Dawn EOS MALS detector (Wyatt Technologies) and a differential refractive index (DRI) detector 2414 (Waters). The laser source of the MALS has a nominal power of $25 \mathrm{~mW}$, and operates at $690 \mathrm{~nm}$, the LED of the DRI emits at $880 \mathrm{~nm}$. The separation was carried out on a set of three polystyrene divinyl benzene (PSDVB) columns Phenogel Linear(2) (5- $\mu$ m particle-diameter mixed bed pores columns, $\mathrm{L} \times \mathrm{D} 300 \mathrm{~mm} \times 4.6 \mathrm{~mm}$, Phenomenex) preceded by a guard column Phenogel $(5-\mu \mathrm{m}, \mathrm{L} \times \mathrm{D} 30 \mathrm{~mm} \times 4.6 \mathrm{~mm}$, Phenomenex). The columns compartment and the Dawn EOS were maintained at $60^{\circ} \mathrm{C}$, the DRI was set to $55^{\circ} \mathrm{C}$. The mobile phase, $\mathrm{N}, \mathrm{N}$ dimethylacetamide with $0.5 \%$ lithium chloride (wt/vol) ( $\mathrm{LiCl} / \mathrm{DMAc}$ ) was filtered through $0.45 \mu \mathrm{m}$ pore PTFE filters (Millipore) prior to use. The system was operated at a flow rate of $0.4 \mathrm{~mL} \mathrm{~min}^{-1}$ with an injection volume of $100 \mu \mathrm{L}$ and a run time of $30 \mathrm{~min}$. The data acquisition was carried out with ASTRA software version 5.3.1.5 (Wyatt Technologies). The value of $d n / d c$ of cellulose in $0.5 \% \mathrm{LiCl} /$ DMAc was experimentally determined online (at $55^{\circ} \mathrm{C}$ and $880 \mathrm{~nm}$ ), in chromatography mode, assuming $100 \%$ sample recovery from the columns, as $0.140 \mathrm{~mL} \mathrm{~g}^{-1}$. This value was preferred in the present case to the value determined in batch mode $\left(0.077 \mathrm{~mL} \mathrm{~g}^{-1}\right)$ [20] with regard to the conformational behaviour of cellulose in the solvent LiCl/DMAc, which is most likely that of a polyelectrolyte complex [21]. Each sample solution was run three times non-consecutively. The repeatability of the method as previously determined was $\mathrm{RSD} \%=2.5$ on the weight-average molar mass $M_{\mathrm{w}}$ for 3 separate cellulose samples analysed two to three times non-consecutively. The dissolution of the paper samples prior to the analysis was carried out in $8 \% \mathrm{LiCl} / \mathrm{DMAc}$ after solvent activation according to a procedure detailed in a previous publication [22]. The molar mass determinations were done for paper P2 only as the presence of significant amounts of lignin in P3 and B1928 hinders the solubility in LiCl/DMAc.

\section{Results and discussion}

\subsection{The treatment with AMDES and its reproducibility}

The capacity to deformation of P2 paper had been previously investigated [19]. Fig. 2, which plots the uptake as a function of the concentration of AMDES, shows that higher concentrations resulted in larger uptakes.

The results reported in Fig. 3 demonstrate that higher uptakes corresponded to increased tensile elongation at break and increased folding endurance. However, the tensile breaking length

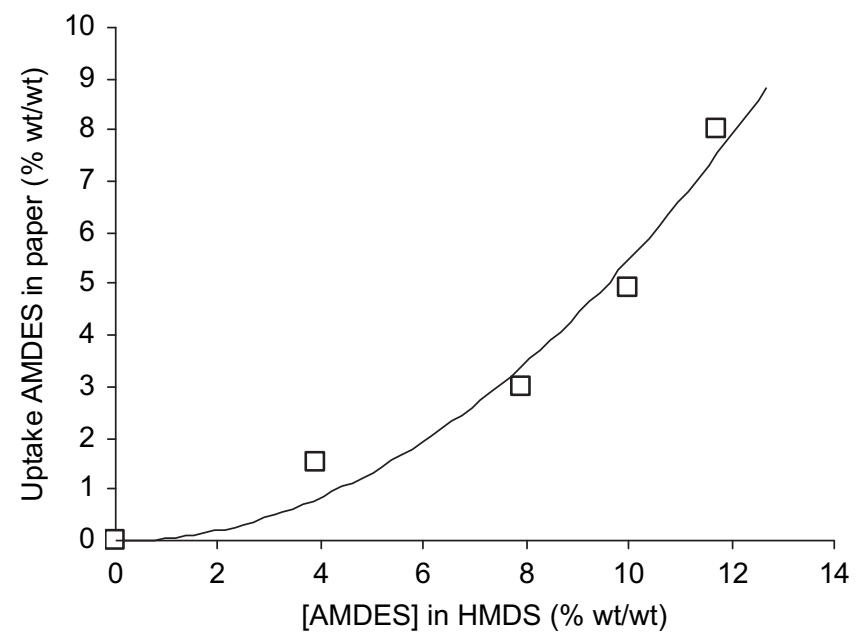

Fig. 2. Uptake of AMDES in the paper (\% wt/wt) as a function of the concentration of AMDES in HMDS (\% wt/wt). 


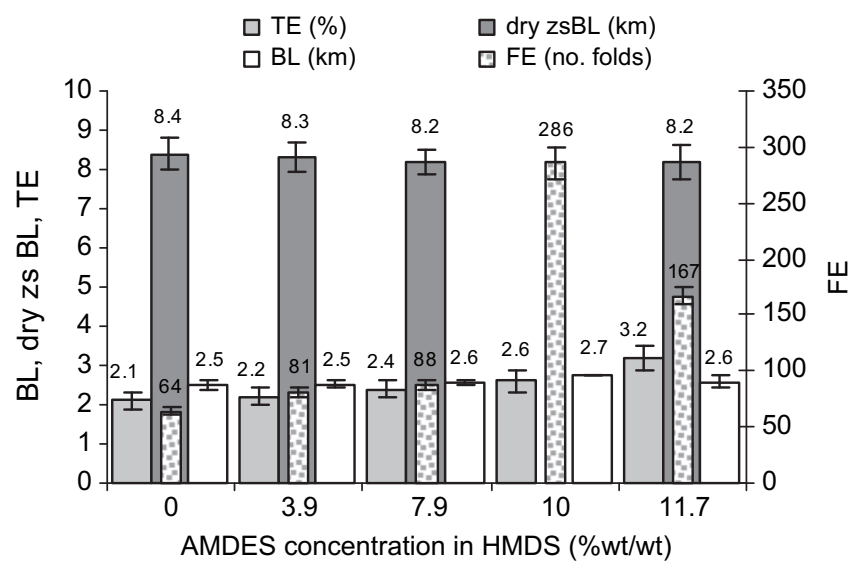

Fig. 3. Mechanical properties of $\mathrm{P} 2$ treated with AMDES (dry zsBL for AMDES $10 \%$ was not determined). Error bars on $\mathrm{BL}$ and dry $\mathrm{zsBL}$ arise from the experimental data obtained.

(BL) and the dry zero-span tensile breaking length $(\mathrm{zsBL})$ remained overall constant over the AMDES concentration range.

This experiment was carried out on one group of papers treated at the same time with the same solution at each AMDES concentration. The reproducibility of the data was then tested on three series of papers treated as different batches with three different solutions of AMDES at the same concentration (7.9\% wt/wt). The mechanical properties of the papers were determined both immediately after treatment, and two months following the treatment (the paper was kept at $23^{\circ} \mathrm{C}$ and $50 \% \mathrm{rH}$ ). Fig. 4 shows that the tensile breaking length and the dry zero-span tensile strength did not increase significantly after the treatment, confirming the results in Fig. 3. This observation could be explained by assuming that AMDES does not form a polymer network on the fibres' surface, assumption which will be discussed further on.
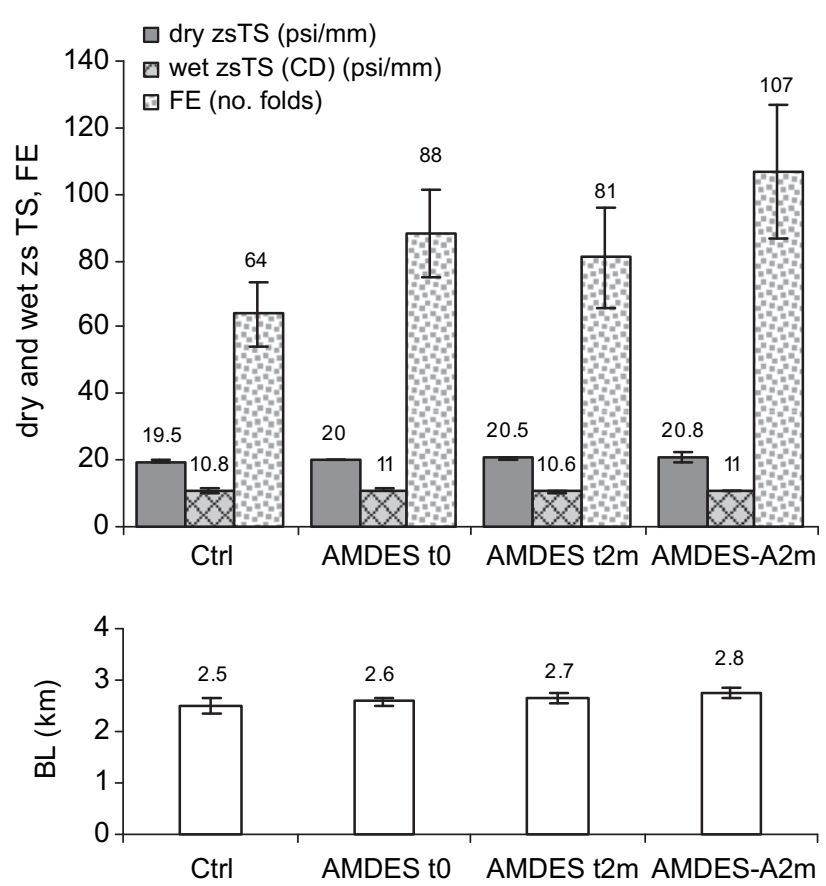

Fig. 4. Mechanical properties of $P 2$ untreated (Ctrl) and $P 2$ treated with AMDES 7.9\% (wt/wt), immediately after treatment with a fresh solution (AMDES $t_{0}$ ), two months after treatment (AMDES $t_{2 m}$ ) and treated with a two-months old solution (AMDES- $A_{2 m}$ ). Error bars arise from the experimental data obtained except on FE (see Experimental section).
The AMDES treatment led to a small increase in the moisture content (MC) of the paper. The average MC of P2 treated was $6.6 \pm 0.1 \%$. P2 which had been immersed in HMDS alone had an MC of $6.4 \pm 0.1 \%$ (data not shown), and control P2 untreated had an MC of $6.2 \pm 0.1 \%$.

The average cold extract $\mathrm{pH}$ of $\mathrm{P} 2$ treated was $9.7 \pm 0.1$, while the alkaline reserve was $9 \pm 1 \mathrm{meq}\left(\mathrm{OH}^{-}\right) / 100 \mathrm{~g}$.

Two months after the AMDES treatment (AMDES $t_{2 m}$ ), the mechanical properties of $\mathrm{P} 2$ were measured again. The data in Fig. 4 show that these properties did not significantly change compared to the measurements done immediately after the treatment. The slight increase observed in the tensile breaking length fell within the experimental error.

In order to investigate the shelf-life of the AMDES solutions, papers were treated with three different batch solutions of AMDES which had been left standing in brown glass bottles at ambient conditions for two months after their preparation, and the mechanical properties measured. A small increase in the dry zerospan tensile strength of the papers was recorded (AMDES- $A_{2 m}$ ) compared with the papers treated with fresh solutions (Fig. 4), which fell within the limit of precision of the measurement. The wet zerospan tensile strength was virtually unchanged, showing that the intrinsic resistance of the fibres was unaffected within experimental accuracy. The folding endurance increased slightly. A simple explanation for this result would be that the AAAS molecules condensate slowly in solution with time. This could be due to the condensation of the silanol functions, which can occur between polysiloxane molecules but could also occur between those molecules and the cellulosic substrate. A slow reaction of the amine groups with cellulose is also possible. This will be discussed further on.

The standard deviation of the values obtained on the three series of measurements showed that the treatment was rather reproducible in terms of the resulting mechanical properties of the paper.

\subsection{AMDES treatment efficacy on degraded paper}

\subsubsection{Paper acidity}

P2, P3 and B1928 were used in order to explore the role of the acidity as these three papers all have a different acid content. The papers were treated in the same conditions with the same solution of AMDES $11.7 \%$ (wt/wt). The results, which are reported in Table 1, indicate that the least acid paper (P2) has the larger uptake. This can be interpreted as if the AMDES uptake was unrelated to paper acidity. The alkaline reserve was also highest for $\mathrm{P} 2$, which was consistent with the uptake values. Thus, the initial paper acidity does not seem to be the most important parameter that influences the extent of the AMDES uptake. It seems more likely that the latter depends on the paper porosity and on its hydrophilic and hydrophobic properties. P2, which is unsized, is less hydrophobic than P3 and B1928, both of which are sized. This point certainly deserves more attention. The results in Table 1 also confirmed that the AMDES treatment led to an increase in the moisture content of the papers.

Table 1

Chemical properties of the papers treated with AMDES 11.7\% (wt/wt).

\begin{tabular}{lllll}
\hline Sample & $\begin{array}{l}\text { Initial acidity } \\
\left(\mathrm{meq}\left(\mathrm{H}^{+}\right) / 100 \mathrm{~g}\right)\end{array}$ & $\begin{array}{l}\text { Alkaline reserve } \\
\left(\mathrm{meq}\left(\mathrm{OH}^{-}\right) / 100 \mathrm{~g}\right)\end{array}$ & $\mathrm{MC}(\%)$ & $\begin{array}{l}\text { Uptake } \\
(\% \mathrm{wt} / \mathrm{wt})\end{array}$ \\
\hline P2 Ctrl & 0.0 & $\mathrm{n} / \mathrm{a}^{\mathrm{a}}$ & 6.2 & $\mathrm{n} / \mathrm{a}$ \\
P3 Ctrl & 7 & $\mathrm{n} / \mathrm{a}$ & 6.4 & $\mathrm{n} / \mathrm{a}$ \\
B1928 Ctrl & 7 & $\mathrm{n} / \mathrm{a}$ & 5.7 & $\mathrm{n} / \mathrm{a}$ \\
P2 + AMDES & $\mathrm{n} / \mathrm{a}$ & 40 & 7.1 & 8.0 \\
P3 + AMDES & n/a & 26 & 7.8 & 4.5 \\
B1928 + AMDES & n/a & 30 & 7.1 & 6.0 \\
\hline
\end{tabular}

${ }^{\text {a }}$ Not applicable. 

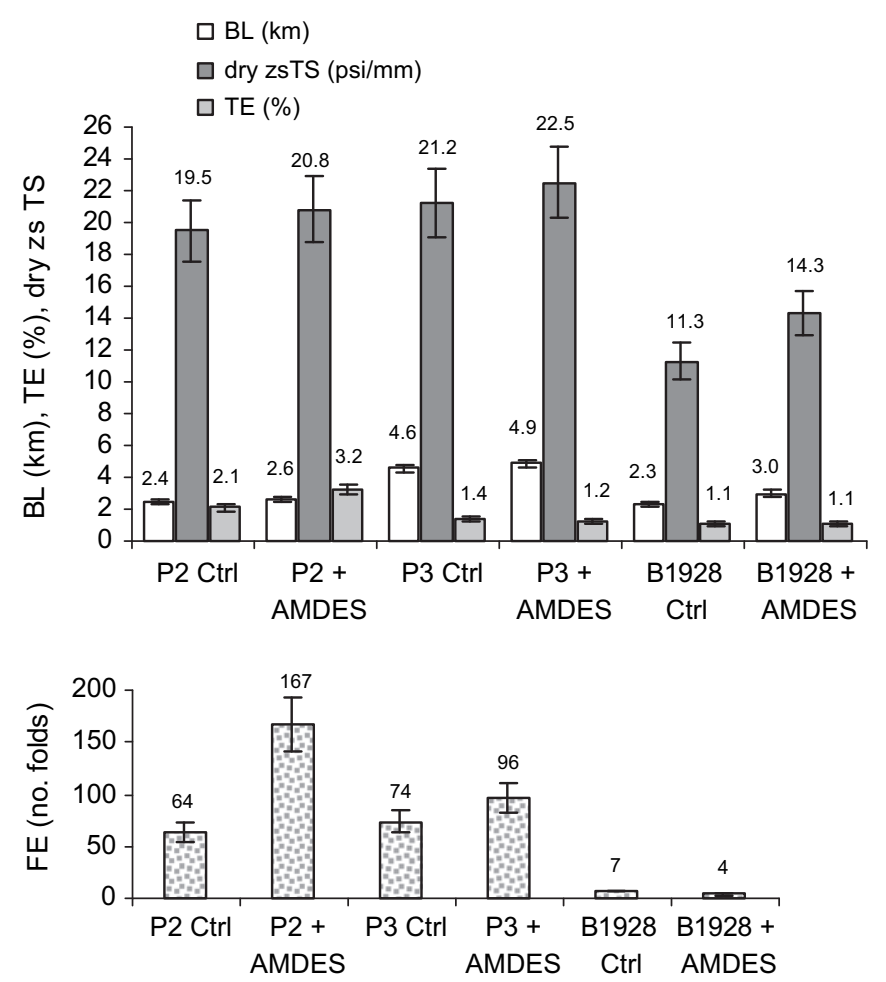

Fig. 5. Mechanical properties of P2, P3 and B1928 with (+AMDES) and without (Ctrl) treatment with AMDES $11.7 \%$ (wt/wt).

The mechanical properties of P2, P3 and B1928 are presented in Fig. 5. A significant increase in the tensile breaking length of B1928 after treatment (22\%) was observed. The dry zero-span tensile strength of P2 and P3 increased slightly after the treatment, and somewhat more significantly in the case of B1928. Consequently, the increase in the tensile breaking length of B1928 after treatment cannot be directly assigned to an increase of the intrinsic resistance of the fibres. Only P2 showed a significant increase in the tensile elongation at break, as well as a large increase in folding endurance. This again could be related to the fact that $\mathrm{P} 2$ is unsized. In the case of P3 the folding endurance increase after treatment was lower, and for B1928, it was very low even after treatment.

\subsubsection{Hygrothermally aged paper}

In an attempt to model the effect of the AAAS treatment on degraded (historic) paper, P2 was hygrothermally pre-aged before immersing in AMDES. The physico-chemical data for P2 treated with AMDES in HMDS $10 \%$ (wt/wt) at different pre-ageing durations is reported in Table 2 and Fig. 6. It can be seen that the tensile breaking length of the untreated (control) samples did not appreciably vary with pre-ageing time, i.e. with the extent of paper degradation, within experimental accuracy. However, the folding endurance of the control samples decreased with pre-ageing time, and a measurable acid content of $20 \mathrm{meq}\left(\mathrm{H}^{+}\right) / 100 \mathrm{~g}$ appeared after ten days of pre-ageing. Accordingly, the alkaline reserve was similar for the two and five days pre-aged and treated samples, but was smaller for the ten days pre-aged sample. Indeed the amine moiety of the AMDES was used up by the acidity in the sample.

The treatment with AMDES induced an increase in the moisture content of $\mathrm{P} 2$, which is consistent with previous results, while the AMDES uptake tended to increase with pre-ageing time. The folding endurance after treatment of the control unaged sample increased considerably, and even further with pre-ageing time, while the tensile breaking length remained approximately constant with pre-ageing time. Consequently, it seems that this increase in the folding endurance cannot be attributed to an increase in the bonding energy.

In order to better understand the long-term behaviour of degraded documents when treated with AAAS, the pre-aged and treated P2 papers were subsequently artificially aged during ten days in the same conditions as used for the pre-ageing. The results represented in Fig. 7, which are to be compared with the results in Fig. 6, indicate a similar trend to larger tensile breaking length of the samples pre-aged two, five and ten days, treated with AMDES, and aged again. However, the samples pre-aged fifteen days showed a drop of their tensile breaking length (sample 15-10). The folding endurance increased slightly for the samples pre-aged two days only to decrease again to the initial value for the sample preaged ten days, and below that value for the sample pre-aged fifteen days. It thus appears that the pre-aged paper treated with AMDES shows a behaviour which is coherent with that of the naturally aged book B1928 (Fig. 5), for which the treatment induced an increase in the tensile breaking length yet a small drop in the folding endurance. It can also be noted that the sample pre-aged for ten days, treated with AMDES and aged again showed as good mechanical performances as the control sample untreated unaged.

In order to complete the set of experiments, P2 samples unaged were treated with AMDES $10 \%$ (average uptake of $4.4 \% \mathrm{wt} / \mathrm{wt}$ ) and subsequently aged for various durations. Results are shown in Fig. 8, and are to be compared with those in Fig. 6, which gathers the properties of control P2 unaged and pre-aged. Tensile elongation at break decreased slightly with ageing time, while breaking length increased up to five days of ageing only to decrease roughly to its initial value for the ten days aged sample. After ten days of ageing, the sample treated with AMDES showed approximately the same mechanical resistance as the control P2 (unaged), and much better performances than its untreated aged counterpart (Fig. 6). Thus the treatment with AMDES

Table 2

Properties of pre-aged paper P2 treated with AMDES 10\% (wt/wt).

\begin{tabular}{|c|c|c|c|c|c|}
\hline P2 sample & $\begin{array}{l}\text { Initial acidity } \\
\left(\mathrm{meq}\left(\mathrm{H}^{+}\right) / 100 \mathrm{~g}\right)\end{array}$ & $\begin{array}{l}\text { Alkaline reserve } \\
\left(\mathrm{meq}\left(\mathrm{OH}^{-}\right) / 100 \mathrm{~g}\right)\end{array}$ & $\mathrm{MC}(\%)$ & Weight loss (\%) & Uptake (\% wt/wt) \\
\hline Ctrl unaged & $\cong 0$ & $\mathrm{n} / \mathrm{a}^{\mathrm{a}}$ & 6.2 & 0 & $\mathrm{n} / \mathrm{a}$ \\
\hline Ctrl pre-aged 2 days & $\cong 0$ & $\mathrm{n} / \mathrm{a}$ & 6.4 & 0.32 & $\mathrm{n} / \mathrm{a}$ \\
\hline Ctrl pre-aged 5 days & $\cong 0$ & $\mathrm{n} / \mathrm{a}$ & $\mathrm{nd}^{\mathrm{b}}$ & 0.91 & $\mathrm{n} / \mathrm{a}$ \\
\hline Ctrl pre-aged 10 days & 20 & $\mathrm{n} / \mathrm{a}$ & 5.2 & 1.36 & $\mathrm{n} / \mathrm{a}$ \\
\hline AMDES unaged & $\mathrm{n} / \mathrm{a}$ & 40 & 6.8 & $\mathrm{n} / \mathrm{a}$ & 4.3 \\
\hline AMDES pre-aged 2 days & $\mathrm{n} / \mathrm{a}$ & 47 & 6.4 & $\mathrm{n} / \mathrm{a}$ & 3.6 \\
\hline AMDES pre-aged 5 days & $\mathrm{n} / \mathrm{a}$ & 48 & 6.5 & $\mathrm{n} / \mathrm{a}$ & 4.7 \\
\hline AMDES pre-aged 10 days & $\mathrm{n} / \mathrm{a}$ & 33 & 7.0 & $\mathrm{n} / \mathrm{a}$ & 5.0 \\
\hline AMDES pre-aged 15 days & $\mathrm{n} / \mathrm{a}$ & nd & nd & $\mathrm{n} / \mathrm{a}$ & 5.9 \\
\hline
\end{tabular}

a Not applicable.
b Not determined. 


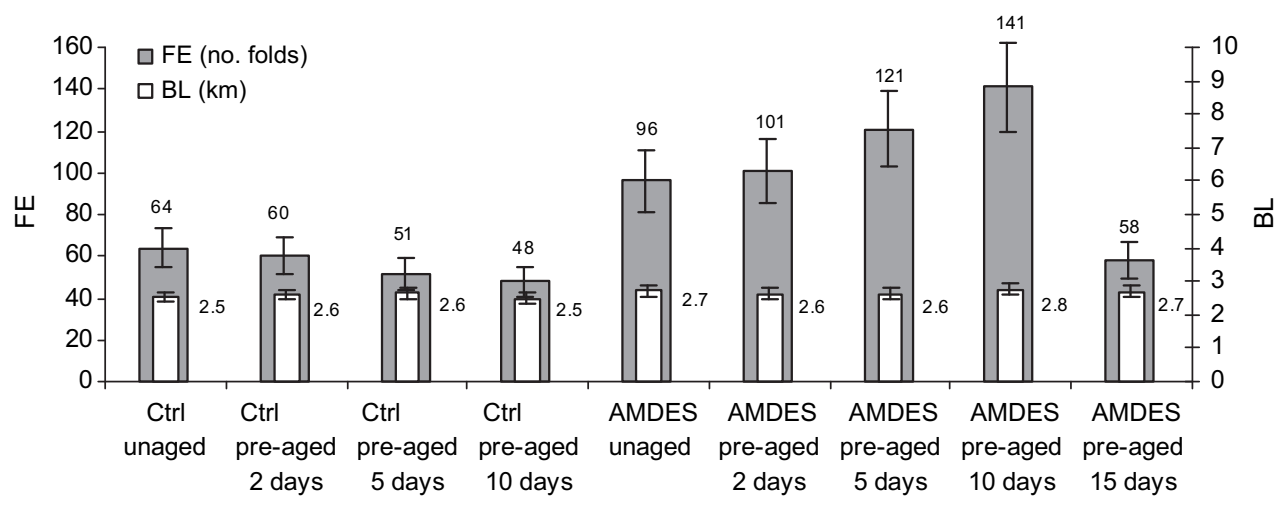

Fig. 6. Mechanical properties of pre-aged paper P2 before and after treatment with AMDES 10\% (wt/wt).

imparted intrinsic resistance to the paper vis-à-vis the degradation incurred during the artificial ageing. However, as expected, a consumption of the alkaline reserve occurred during the ageing, as well as a decrease of the molar mass of the cellulose. The weightaverage molar mass $\left(M_{\mathrm{w}}\right)$ was $2.91 \times 10^{-5} \mathrm{~g} \mathrm{~mol}^{-1}$ for the untreated sample unaged, $2.60 \times 10^{-5} \mathrm{~g} \mathrm{~mol}^{-1}$ after two days (a decrease of $11 \%$ ), and $1.88 \times 10^{-5} \mathrm{~g} \mathrm{~mol}^{-1}$ after ten days (a decrease of $36 \%$ ). While $M_{\mathrm{W}}$ of the sample treated with AMDES was $2.77 \times 10^{-5} \mathrm{~g} \mathrm{~mol}^{-1}$ after two days, it was $2.24 \times 10^{-5} \mathrm{~g} \mathrm{~mol}^{-1}$ after ten days, which was higher by $16 \%$ than that of the untreated sample aged ten days. For the unaged sample, $M_{\mathrm{w}}$ values were rather similar before and after treatment, which shows that AMDES did not promote the formation of new covalent bonds between cellulose macromolecules.

It was reported above that pre-ageing seems to favour AMDES uptake (Table 2). This increase in uptake should bring in turn improved mechanical resistance such as better folding endurance (Fig. 3). This is true for papers pre-aged two days, treated and subsequently aged for ten days (Fig. 7). The beneficial effect of a higher uptake was not observed in the case of longer pre-ageing time (assays $5-10$ and $10-10$ ). Indeed, Fig. 7 shows that the values of breaking length and folding endurance are hardly better than for the control sample. It is worth recalling here that the fibres are increasingly degraded at longer ageing times as shown by the decreasing molar mass values of the cellulose macromolecules. In other words, the treatment of paper with AMDES can compensate for the loss of mechanical resistance brought upon by ageing. However, sample '15-10' in Fig. 7 shows that the degradation due

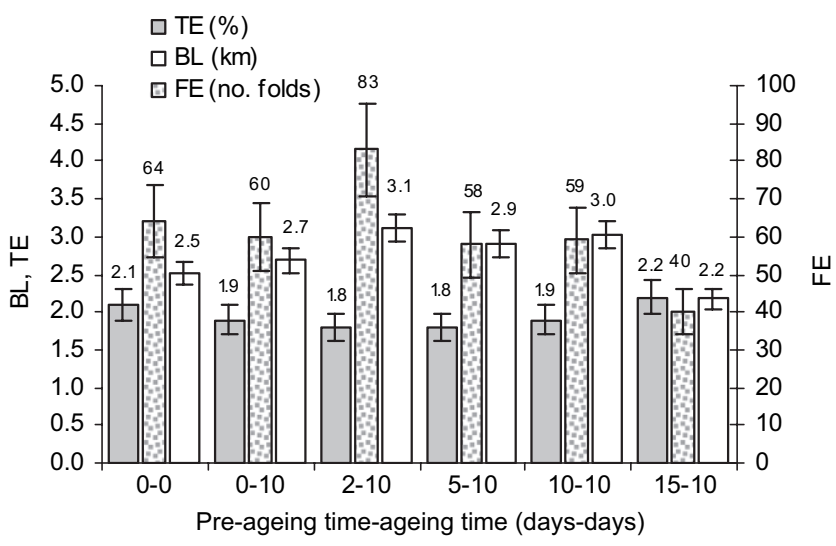

Fig. 7. Mechanical properties of P2 papers: $\operatorname{Ctrl}(0-0)$; aged 10 days $(0-10)$; pre-aged $(2,5,10$ and 15 days), then treated with AMDES $10 \%$ (wt/wt) and subsequently aged again during 10 days $(2-10,5-10,10-10,15-10$, respectively). to fifteen days of pre-ageing is too high to be fully compensated by the AMDES treatment.

At this point, it is worth synthesizing the most important results so far. It can be observed that upon treatment with AMDES, P2 (unaged) underwent a significant improvement of its mechanical properties (Figs. 3 and 5). Upon artificial ageing, the treated paper exhibited mechanical properties which were as good as those of the control (unaged and untreated), and most often better (Figs. 6 and 8). After ageing ten days, the folding endurance of $\mathrm{P} 2$ had decreased by $25 \%$ (Fig. 6) while the tensile breaking length was unaffected. It is also noteworthy that the treated and aged samples showed significantly improved mechanical characteristics compared to those of the aged control samples (Figs. 6 and 7). Finally, upon further ageing (ten days), the pre-aged and treated paper showed a folding endurance which was comparable to that of the control P2, while the tensile breaking length was slightly higher (Fig. 7). The beneficial effect of the AMDES treatment on unaged paper as well as on aged paper was thus clearly demonstrated.
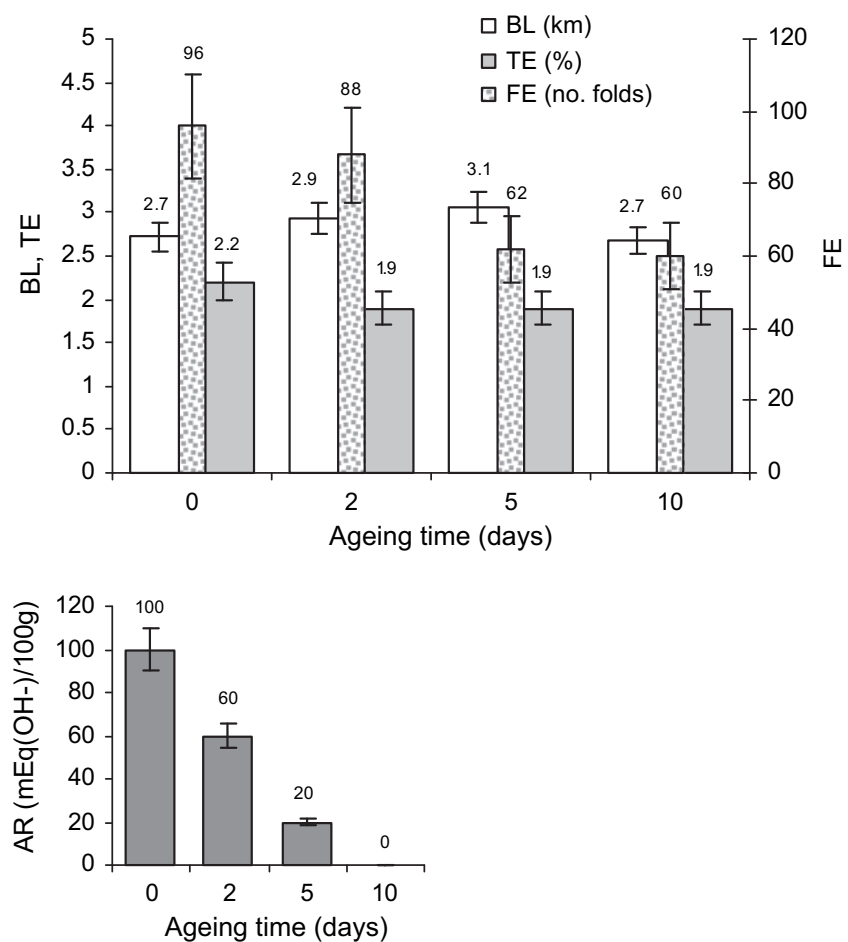

Fig. 8. Properties of P2 Ctrl and P2 treated with AMDES 10\% (wt/wt) and aged. 


\subsubsection{Chemically oxidised paper with $\mathrm{NaOCl}$}

In order to better understand the nature of the interaction between cellulose and AMDES, an evaluation of how the functional groups of cellulose contribute to the performances achieved with the AMDES treatment was necessary. A modification of the hydroxyl groups on cellulose was carried out by chemical oxidation using sodium hypochlorite $(\mathrm{NaOCl})$. Attack of cellulose with $\mathrm{NaOCl}$ has been characterised to occur randomly in the accessible areas of the fibres (amorphous regions), and lead to considerable chain scission as well as to the formation of carbonyl groups on cellulose, and to the production of short chain organic acids [23]. At neutral $\mathrm{pH}$, the carbonyl functions created are mostly aldehyde and ketone groups. The nature and the quantity of the carbonyl functions created depend largely on the $\mathrm{pH}$ at which the oxidation is carried out.

A first hypothesis is that the primary amine group on AMDES can react with carbonyl groups created on cellulose, thus contributing to the strengthening of the paper. The bonding between the polysiloxane molecules and the cellulose network could then occur, either through covalent or ionic bonding. The second hypothesis is that the AMDES could interact through hydrogen bonding. According to this hypothesis, the strengthening effect could then be due to local concentration of AMDES oligomers and polymers in the fibre intercrossing areas.

$\mathrm{P} 2$ was immersed in $\mathrm{NaOCl}$ at $1.3 \%$ active chlorine, at $\mathrm{pH} 7.0$ during 30 and $120 \mathrm{~min}$. At neutral $\mathrm{pH}$, the attack on cellulose is very aggressive, the immersion time was thus considerably decreased. It was verified that the oxidation did not produce significant carboxyl groups formation on the cellulose, as the initial acidity of a P2 paper oxidised in such conditions for $4 \mathrm{~h}$ was measured as $1.6 \mathrm{meq}\left(\mathrm{H}^{+}\right)$/ 100 g. The results are reported on Fig. 9.

The oxidation treatment strongly affected the mechanical properties of $\mathrm{P} 2$. The fibres were extremely degraded as shown by the complete fall of the wet zero-span tensile strength already after $30 \mathrm{~min}$ in $\mathrm{NaOCl}$. Some dry zero-span tensile strength remained, which decreased with oxidation time. The latter was probably due to residual inter-fibre contact energy. As expected, the oxidised papers also lost folding endurance, completely so after $120 \mathrm{~min}$ in
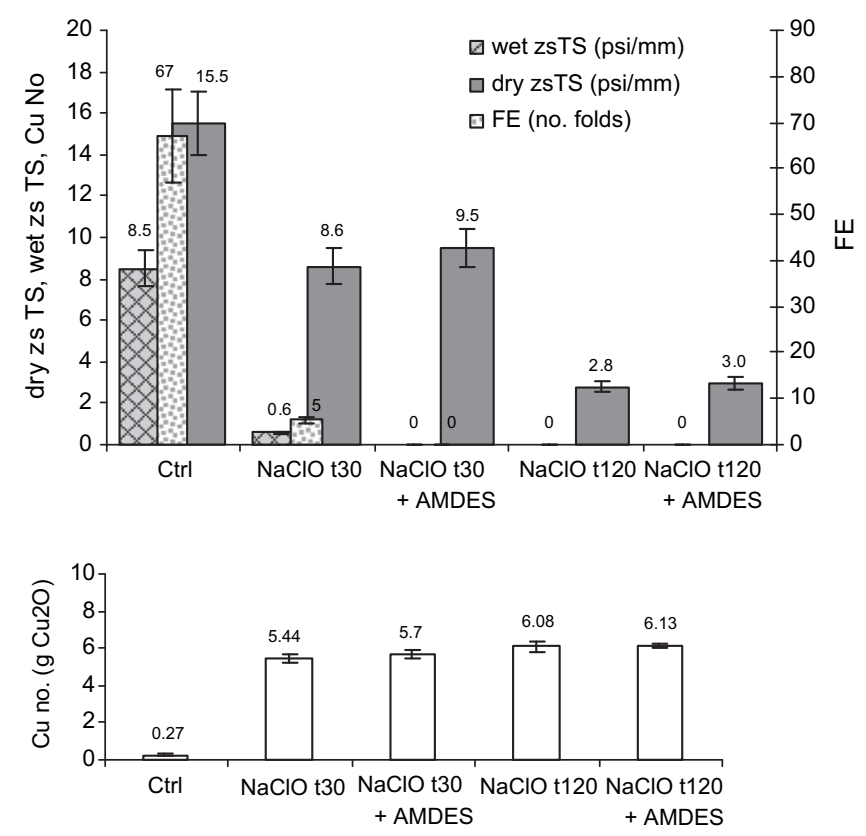

Fig. 9. Mechanical properties of $\mathrm{P} 2$ oxidised with $\mathrm{NaOCl}(1.3 \%$ active $\mathrm{Cl})$ at $\mathrm{pH}=7.0$ for 30 and $120 \mathrm{~min}$, and subsequently treated with AMDES 10\% (wt/wt). Error bars on $\mathrm{Cu}$ No arise from the experimental data obtained.
Table 3

Mechanical properties of P2 after AMDES treatment 10\% (wt/wt) and artificial ageing with $\mathrm{NO}_{\mathrm{x}} 50$ ppm for 5 days.

\begin{tabular}{lll}
\hline P2 sample & $\begin{array}{l}\text { Initial acidity } \\
\left(\mathrm{meq}\left(\mathrm{H}^{+}\right) / 100 \mathrm{~g}\right)\end{array}$ & $\begin{array}{l}\text { Alkaline reserve } \\
\left(\mathrm{meq}\left(\mathrm{OH}^{-}\right) / 100 \mathrm{~g}\right)\end{array}$ \\
\hline Ctrl unaged & 0 & $\mathrm{n} / \mathrm{a}^{\mathrm{a}}$ \\
Ctrl aged & 20 & $\mathrm{n} / \mathrm{a}$ \\
AMDES unaged & $\mathrm{n} / \mathrm{a}$ & 35 \\
AMDES aged & $\mathrm{n} / \mathrm{a}$ & 5 \\
\hline
\end{tabular}

a Not applicable.

$\mathrm{NaOCl}$. The copper number of the oxidised papers increased significantly, to a value of 5.44 after $30 \mathrm{~min}$ in $\mathrm{NaOCl}$, and further, to 6.08 after 120 min confirming the enhanced formation of carbonyl functions on cellulose.

The treatment with AMDES did not appreciably improve the mechanical resistance of these oxidised papers. The dry zero-span tensile strength and the folding endurance improved only very slightly after treatment for each respective oxidised sample. However, due to the main result that the alkaline reserve is approximately as could be expected from the uptake, it shows that the amine groups are present and free for deacidification and bonding. This conclusion was consistent with the copper number values which, after oxidation, were similar for the untreated and treated samples. Thus the AMDES treatment left the carbonyl groups on cellulose free to titration. This demonstrates that any possible reaction of AMDES with the carbonyl functions does not lead to covalent bonding but rather to a weak type of bond. It can thus be concluded that the nature of the chemical functions present on the cellulose only has a negligible impact, if any, on the resulting properties of the paper after treatment with AMDES.

\subsubsection{Paper artificially aged with $\mathrm{NO}_{x}$}

The results reported earlier showed that while AMDES brings some improvement of the mechanical resistance, the protection
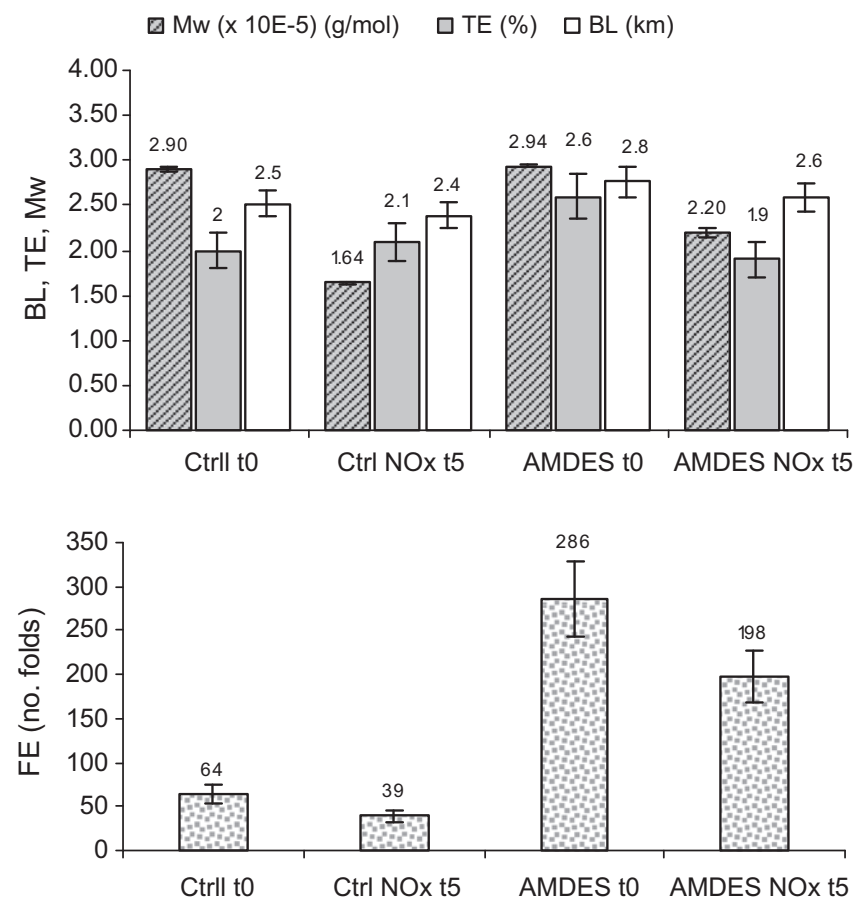

Fig. 10. Mechanical properties and $M_{\mathrm{W}}$ of P2 control and treated with AMDES 10\% (wt/ $\mathrm{wt}$ ) before $\left(\mathrm{t}_{0}\right)$ and after 5 days of pollution ageing $\left(\mathrm{NO}_{\mathrm{x}} \mathrm{t}_{5}\right)$. Error bars on $M_{\mathrm{w}}$ arise from the experimental data obtained. 
effect in terms of folding endurance is significant for unoxidised papers but rather null for very oxidised papers.

It was decided to submit P2 to a different type of degradation treatment in order to document further the aspect of degraded cellulose and its interaction with AMDES.

Table 3 and Fig. 10 show the data for the characteristics of the paper after artificial ageing with nitrogen oxides during five days. $\mathrm{NO}_{\mathrm{x}}$ is reported to provoke a drop in the mechanical properties and in the molar mass of cellulose $[2,24]$. An increase in the acid content and a decrease in the folding endurance were observed. The AMDES treatment brought a clear protection against the drop of the mechanical resistance. However, this protection was obtained at the expense of the alkaline reserve, which was almost completely depleted after the polluted atmosphere ageing cycle. It can be seen that upon ageing with nitrogen oxides, the AMDES treated papers have a much larger folding endurance than the untreated papers $(80 \%$ increase), which confirms previous results [14]. This effect could be attributed to an interaction via hydrogen bonding, as proposed above.

Table 3 shows that P2 papers, after ageing with $\mathrm{NO}_{\mathrm{x}}$ and subsequently treated with AMDES, still have an alkaline reserve of $5 \mathrm{meq}\left(\mathrm{OH}^{-}\right) / 100 \mathrm{~g}$, that is an alkaline state in which the carboxyl groups are under the form of carboxylates. This again supports the fact that the improvement of the mechanical resistance (Fig. 10) is to be assigned to hydrogen bonding.

Fig. 10 shows the values of $M_{\mathrm{w}}$ for the $\mathrm{NO}_{\mathrm{x}}$ aged samples. It appears clearly that the AMDES treatment had a protective effect on the paper towards the degradation, with $M_{\mathrm{w}}$ of the paper treated with AMDES and polluted $25.5 \%$ higher than that of the control polluted. $M_{\mathrm{W}}$ of control P2 dropped by $43 \%$ upon the exposure, whereas the drop for P2 treated with AMDES and polluted was of $25 \%$.

These observations are not in contradiction with the results in Fig. 5, for paper with low acidity content, where the most acidic sample did not exhibit the highest strength gain.

\section{Conclusions}

In this study, it was shown that the treatment of pure cellulose paper with AMDES not only provided deacidification and significant alkaline reserve deposition, but also improved some of the mechanical resistance of the paper such as tensile strength and folding endurance. Tensile elongation at break was also often improved. However, it was shown that for highly degraded papers, the extent of the improvement was smaller than for unaged papers. The folding endurance of the paper was smaller at higher ageing times but increased when the paper was treated with AMDES after ageing. It was also shown that upon further ageing of a pre-aged and treated paper, the folding endurance decreased, but only to the extent of approximately the initial value of the unaged, untreated control paper, except in the case of a severe pre-ageing. As expected, a decrease was observed in the molar mass of cellulose with artificial ageing (hygrothermal, pollution with $\mathrm{NO}_{\mathrm{x}}$ and oxidation treatment). This observation was true also for the papers treated with AMDES, which would tend to demonstrate that the improvement in the mechanical characteristics cannot be assigned to the formation of covalent bonding between the AMDES molecules and the cellulose macromolecules. When the mechanical resistance of the fibres was strongly affected by chemical oxidation in conditions where carboxyl groups are preferentially created on cellulose $(\mathrm{NaOCl}$ at alkaline $\mathrm{pH})$, the introduction of AMDES improved the folding endurance of the paper. When the oxidation with $\mathrm{NaOCl}$ was carried out at neutral $\mathrm{pH}$ (conditions in which aldehyde and ketone groups are predominantly created on cellulose) the intrinsic mechanical resistance of the fibres severely decreased and any positive effect on the folding endurance was weak, in the limit of the sensitivity of the measurements, at least for a mildly oxidised paper. The nature of the oxidised groups formed on the cellulose during the ageing and the oxidation does not seem to play a significant role in the strengthening effect which was rather observed when the fibres were not highly degraded.

It can be concluded that the strengthening effect of AMDES mainly arises from the energy due to hydrogen bonding, which most likely seems to be the mechanism operating at the molecular scale even at low AMDES concentration. The best support to this conclusion is the fact that the wet zero-span tensile strength remained constant for a paper treated with AMDES compared to its untreated counterpart, which evidences that the bonding energy brought by the AMDES treatment was released in water.

It was shown by this research that when the paper becomes mechanically weak due to ageing, the strengthening effect of AMDES progressively vanishes. The ongoing and future research is geared towards finding a solution to imparting better mechanical properties to severely degraded papers.

\section{Acknowledgments}

The French Ministry of Culture is gratefully acknowledged for a research grant. L. Lee is warmly thanked for technical assistance.

\section{References}

[1] Havermans J. Effects of air pollutants on the accelerated ageing of cellulosebased materials. Restaurator, Int J Preserv Lib Archival Mater 1996;16:209-33.

[2] Dupont A-L, Barthez J, Jerosch H, Lavédrine B. Testing CSC book saver, a commercial deacidification spray. Restaurator, Int J Preserv Lib Archival Mater 2002;23:39-47.

[3] Zou X. During storage and shipping, nitrogen oxides can cause rapid yellowing and degradation of pulp and paper products. Pulp Pap Can 2004;105(3):51-4.

[4] Dupont A-L, Tétreault J. Cellulose degradation in an acetic acid environment. Stud Conserv 2000;45:201-10.

[5] Carter H, Begin P, Grattan D. Migration of volatile compounds through stacked sheet of paper during accelerated ageing. Part 1: acid migration at $90^{\circ} \mathrm{C}$. Restaurator, Int J Preserv Lib Archival Mater 2000;21:77-84.

[6] Dupont A-L, Egasse C, Morin A, Vasseur E. Comprehensive characterization of cellulose- and lignocellulose- degradation products in aged papers: capillary zone electrophoresis of low-molar mass organic acids, carbohydrates, and aromatic lignin derivatives. Carbohydr Polym 2007;68(1):1-16.

[7] Strlic M, Kralj Cigić I, Kolar J, de Bruin G, Pihlar B. Non-destructive evaluation of historical paper based on $\mathrm{pH}$ estimation from VOC emissions. Sensors 2007:7:3136-45

[8] Ramalho O, Dupont A-L, Egasse C, Lattuati-Derieux A. Emission rates of volatile organic compounds from paper. E-Preserv Sci J 2009;6:53-9.

[9] Rousset E, Ipert S, Cheradame H. Mass deacidification of papers and books II deacidification in the liquid phase using aminosilanes. Restaurator, Int J Preserv Lib Archival Mater 2004;25:104-18.

[10] Cheradame H, Ipert S, Rousset E. Mass deacidification of papers and books I study of the limitations of the gas phase processes. Restaurator, Int J Preserv Lib Archival Mater 2003;24:227-39.

[11] Anastas PT, Warner JC. Green chemistry: theory and practice. New York: Oxford University Press; 1998.

[12] PatentschriftDE 4104515C1, Battelle Institut, 1992.

[13] Cheradame H. Some progress towards a multifunctional mass deacidification process. Int Preserv News 2009;48:5-8.

[14] Ipert S, Dupont A-L, Lavédrine B, Bégin P, Rousset E, Cheradame H. Mass deacidification of papers and books. IV. A study of papers treated with aminoalkylalkoxysilanes and their resistance to ageing. Polym Degrad Stab 2006;91 (12):3448-55

[15] Ipert S, Rousset E, Cheradame H. Mass deacidification of papers and books III study of a paper strengthening process and deacidification process with amino alkyl alkoxy silanes. Restaurator, Int J Preserv Lib Archival Mater 2005;26:250-64.

[16] Bennevault-Celton V, Maciejak $O$, Desmazières $B$, Cheradame $H$. Condensation of alkoxysilanes in alcoholic media I. Oligomerization of dimethyldiethoxysilanes. Polym Int 2010;59:43-54.

[17] Bennevault-Celton V, Maciejak O, Desmazières B, Cheradame H. Condensation of alkoxysilanes in alcoholic media II. Oligomerization of aminopropylmethyldiethoxysilane and co-oligomerization with dimethyldiethoxysilane. Polym Int 2010;59(9):1273-81.

[18] Rakotonirainy $M$, Dupont A-L, Lavédrine B, Ipert $S$, Cheradame $H$. Mass deacidification of papers and books: V. fungistatic properties of papers treated with aminoalkylakoxysilanes. J Cult Herit 2008;9:54-9.

[19] STEP project CT 90 90-0100. TNO report BU3.94/1068/JH. 
[20] Dupont A-L, Harrison G. Conformation and $d n / d c$ determination of cellulose in $\mathrm{N}, \mathrm{N}$-dimethylacetamide containing lithium chloride. Carbohydr Polym 2004; 58(3):233-43.

[21] Striegel AM. Advances in the understanding of the dissolution mechanism of cellulose in DMAc/LiCl. J Chil Chem Soc 2003;48(1):73-7.

[22] Dupont A-L. Cellulose in lithium chloride/, $\mathrm{N}$-dimethylacetamide, optimisation of a dissolution method using paper substrates and stability of the solutions. Polymer 2003;44(15):4117-26.
[23] Nevell TP. In: Nevell TP, Zeronian SH, editors. Cellulose chemistry and its application, chapter 10: oxidation of cellulose. New York: J. Wiley; 1985. p. 259.

[24] Jerosch $\mathrm{H}$, Lavédrine B, Cherton J-C. The use of size exclusion chromatography (SEC) for the evaluation of paper degradation caused by nitrogen oxides in comparison with other methods. In: Daniels V, Donithorne A, Smith P, editors. Works of art on paper, books, documents and photographs. Techniques and conservation congress of the International Institute for Conservation. London: Int. Inst. for Conservation; 2002. p. 108-13. 